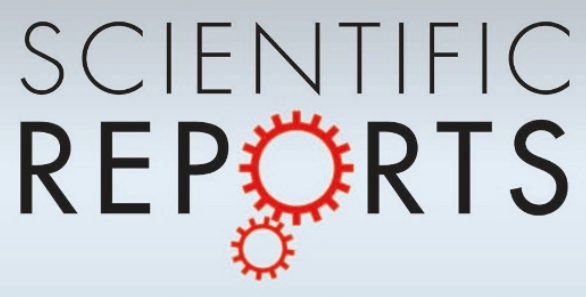

OPEN

SUBJECT AREAS:

SOLUTION-STATE NMR

MOLECULAR CONFORMATION

Received

14 September 2014

Accepted

26 January 2015

Published

2 March 2015

Correspondence and requests for materials should be addressed to N.S.B. (neelsb@icgeb. res.in)

\title{
Dynamic association of PfEMP1 and KAHRP in knobs mediates cytoadherence during Plasmodium invasion
}

\author{
Akshay Kumar Ganguly', Priyatosh Ranjan², Ashutosh Kumar² \& Neel Sarovar Bhavesh'
}

\begin{abstract}
'International Centre for Genetic Engineering and Biotechnology (ICGEB), Aruna Asaf Ali Marg, New Delhi, India - 110067
${ }^{2}$ Department of Biosciences and Bioengineering, Indian Institute of Technology (IIT), Bombay, Mumbai, India - 400076.
\end{abstract}

Plasmodium falciparum infected erythrocytes display membrane knobs that are essential for their adherence to vascular endothelia and for prevention of clearance by the spleen. The knob associated histidine rich protein (KAHRP) is indispensable to knob formation and has been implicated in the recruitment and tethering of $P$. falciparum erythrocyte membrane protein-1 (PfEMP1) by binding to its cytoplasmic domain termed VARC. However, the precise mechanism of interaction between KAHRP and VARC is not very well understood. Here we report that both the proteins co-localize to membrane knobs of $P$. falciparum infected erythrocytes and have identified four positively charged linear sequence motifs of high intrinsic mobility on KAHRP that interact electrostatically with VARC in solution to form a fuzzy complex. The current study provides molecular insight into interaction between KAHRP and VARC in solution that takes place at membrane knobs.

M alaria is a disease of global prevalence with $\sim 207$ million cases being reported in 2012 alone. Among its causative agents, Plasmodium falciparum is the most lethal of known malarial parasites, being responsible for about $98 \%$ cases in Africa and $65 \%$ cases globally ${ }^{1}$. The pathogenicity of P. falciparum is, in part, due to its property of avoiding splenic defenses by sequestration of infected erythrocytes in the microvasculature of organs; a phenomenon known as cytoadherence. This sequestration causes vascular blockage and is a direct cause of cerebral and placental malaria ${ }^{2,3}$. Sequestered erythrocytes are characterized by biomechanical changes in their cytoskeleton and cell surface that are crucial for the survival of the parasite ${ }^{4}$.

Cytoadhesion is mediated by the large $(200-350 \mathrm{kDa})$, antigenically variant $P$. falciparum erythrocyte membrane protein-1 (PfEMP1), which can bind to host receptors on the surface of vascular endothelial cells ${ }^{5}$. Exported PfEMP1 is seen to localize to specific regions on the erythrocyte plasma membrane called knobs ${ }^{6-8}$. Knobs are cup shaped electron dense protrusions of the membrane that aid in anchoring PfEMP1. Past studies have shown that knobs are essential for cytoadherence under physiological flow conditions ${ }^{9}$. Inside the cell, knob primarily consists of an $80-105 \mathrm{kDa}$ exported parasite protein called knob associated histidine-rich protein (KAHRP) ${ }^{10-11}$. The KAHRP primary structure ${ }^{11-12}$ consists of a signal sequence targeting the parasitophorous vacuole, a plasmodium export element, a histidine rich region (K1), a central lysine rich repeat region (K2) and a C-terminal repeat region (K3) (Fig 1). K1 and K2 can separately bind to the acidic terminal sequence (ATS) of PfEMP1 (termed VARC) located on the cytoplasmic face of plasma membrane of $P$. falciparum-infected erythrocytes ${ }^{13}$. Biochemical studies have shown that the N-terminal region of K2 of KAHRP (termed K2A) binds to the first 291 residues of VARC (comprising VARC A and VARC B) by a moderate affinity interaction that is $\mathrm{pH}$ dependent ${ }^{14-15}$.

The current study focuses on the interaction between K2A and VARC in solution and its implications on the mechanism of PfEMP1 tethering to knobs, using a combination of solution-state nuclear magnetic resonance (NMR) spectroscopy, calorimetry and immunofluorescence microscopy.

\section{Results}

K2A possesses two tandem repeats with overlapping resonance frequencies. To gain molecular insight into the role of K2A, the central lysine-rich repeat region of KAHRP (Fig. 1a), it was over-expressed, purified and solutionstate NMR spectroscopy was performed. The 2D $\left[{ }^{15} \mathrm{~N},{ }^{1} \mathrm{H}\right]$ HSQC spectrum of K2A (Supplementary Fig. S1a) showed poor dispersion for the backbone amide resonances. During the course of obtaining backbone resonance assignments for $\mathrm{K} 2 \mathrm{~A}$, it was observed that the chemical shift for a stretch of amino acids from positions $\mathrm{H} 382$ to K408 overlapped with those from positions $\mathrm{H} 409$ to K435 due to their being nearly perfect tandem repeats of each 
a
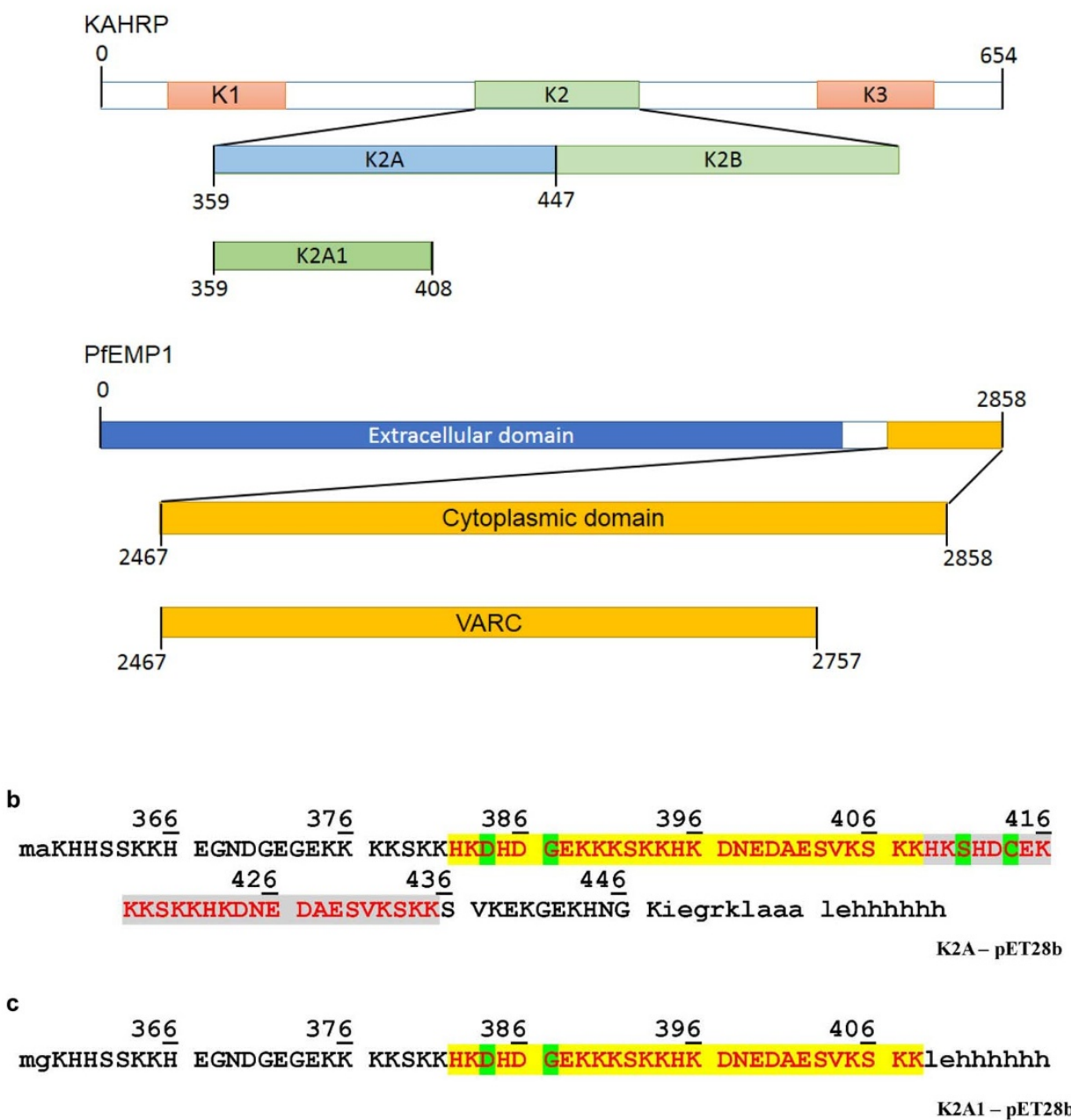

Figure 1 Domain architecture of K2A, K2A1 and VARC. (a) Schematic representations of KAHRP and PfEMP1 depicting cloned regions K2A, K2A1 and VARC. (b) Sequence of cloned K2A polypeptide showing tandem repeats (highlighted in yellow and grey). Amino acids highlighted in green represent the differences between the two repeats. Amino acids in lowercase are encoded by the vector pET28b. (c) Sequence of cloned K2A1 polypeptide, containing the first of two tandem repeats.

other (Fig. 1b) and hence, in similar chemical environments. The problem in obtaining sequence-specific resonance assignment posed by the tandem repeats of $\mathrm{K} 2 \mathrm{~A}$ was overcome by cloning the first $\left(5^{\prime}\right)$ repeat of $\mathrm{K} 2 \mathrm{~A}$ independently (termed $\mathrm{K} 2 \mathrm{~A} 1$ ) (Fig. 1c). The rationale for truncating $\mathrm{K} 2 \mathrm{~A}$ is corroborated by the fact that the interaction of $\mathrm{K} 2 \mathrm{~A}$ with VARC is largely electrostatic in nature ${ }^{15}$ and is unlikely to be altered on truncation, given that the theoretical isoelectric $\mathrm{pI}$ values of both K2A and K2A1 are identical (9.77) and both possess a net positive charge $(+16.8$ and +9.4 , respectively $)$ at $\mathrm{pH} 7$. Full length K2A has a mean theoretical charge of +0.198 per residue while that for K2A1 was +0.188 , ranging from values of -0.6 to +0.8 . A comparison of the sequence-specific charge profiles of $\mathrm{K} 2 \mathrm{~A}$ and K2A1 (Supplementary Fig. S1b) showed an oscillating charge distribution along the length of both polypeptides, with discrete regions of high positive charge separated by negatively charged stretches. The similarity in charge distribution between the pair of positively charged tandem repeats suggested that only one of them would be sufficient for electrostatic interactions with acidic residues on VARC.

K2A1 is an intrinsically disordered protein. Poor dispersion and narrow line-widths of backbone amide resonances in the $2 \mathrm{D}\left[{ }^{15} \mathrm{~N},{ }^{1} \mathrm{H}\right]$ HSQC spectrum of K2A1 revealed the presence of highly unstructured and flexible regions similar to K2A (Fig. 2a). All
NMR spectra for K2A1 and K2A were measured at $278 \mathrm{~K}$ where backbone amide resonances were more dispersed and had better line-widths. A comparison of the 2D $\left[{ }^{15} \mathrm{~N},{ }^{1} \mathrm{H}\right]$ HSQC spectra of $\mathrm{K} 2 \mathrm{~A} 1$ and $\mathrm{K} 2 \mathrm{~A}$ revealed an overlap of large number of backbone amide peaks despite the 48 residue difference in length between the recombinant proteins, further justifying our rationale for truncating K2A (Supplementary Fig. S2).

${ }^{1} \mathrm{H},{ }^{15} \mathrm{~N}$ and ${ }^{13} \mathrm{C}$ backbone and side-chain resonances of $\mathrm{K} 2 \mathrm{~A} 1$ were assigned, except for the NHs of residues K355, K394 and K408. About $\sim 92 \%$ of backbone and $\sim 56 \%$ of side chain resonances were assigned unambiguously. Complete unambiguous side-chain resonance assignment was not possible due to the poor chemical shift dispersion of methylene and methyl protons as well as for side chain $\mathrm{NH}$ resonances that is expected for an intrinsically disordered polypeptide.

Automated NOE resonance assignments were performed using 3D ${ }^{13} \mathrm{C}$-edited $\left[{ }^{1} \mathrm{H}, \mathrm{H}\right]$-NOESY and $3 \mathrm{D}{ }^{15} \mathrm{~N}$-edited $\left[{ }^{1} \mathrm{H},{ }^{1} \mathrm{H}\right]$-NOESY spectra, yielding a total of $151 \mathrm{NOE}$ distance restraints (2.52 per residue) and 257 dihedral restraints for distance geometry calculations. Medium $(1<|\mathrm{i}-\mathrm{j}|<5)$ and long range $(|\mathrm{i}-\mathrm{j}|>4)$ NOEs constituted only $8.61 \%$ and $3.31 \%$ of observed NOEs respectively, the remainder being contributed by intra-residue $(|\mathrm{i}-\mathrm{j}|=0)$ and sequential $(|\mathrm{i}-\mathrm{j}|=1)$ NOEs. Secondary chemical shifts and the absence of mid- and longrange $\left[{ }^{1} \mathrm{H},{ }^{1} \mathrm{H}\right]$ NOEs clearly proved that $\mathrm{K} 2 \mathrm{~A} 1$ is an intrinsically 
a

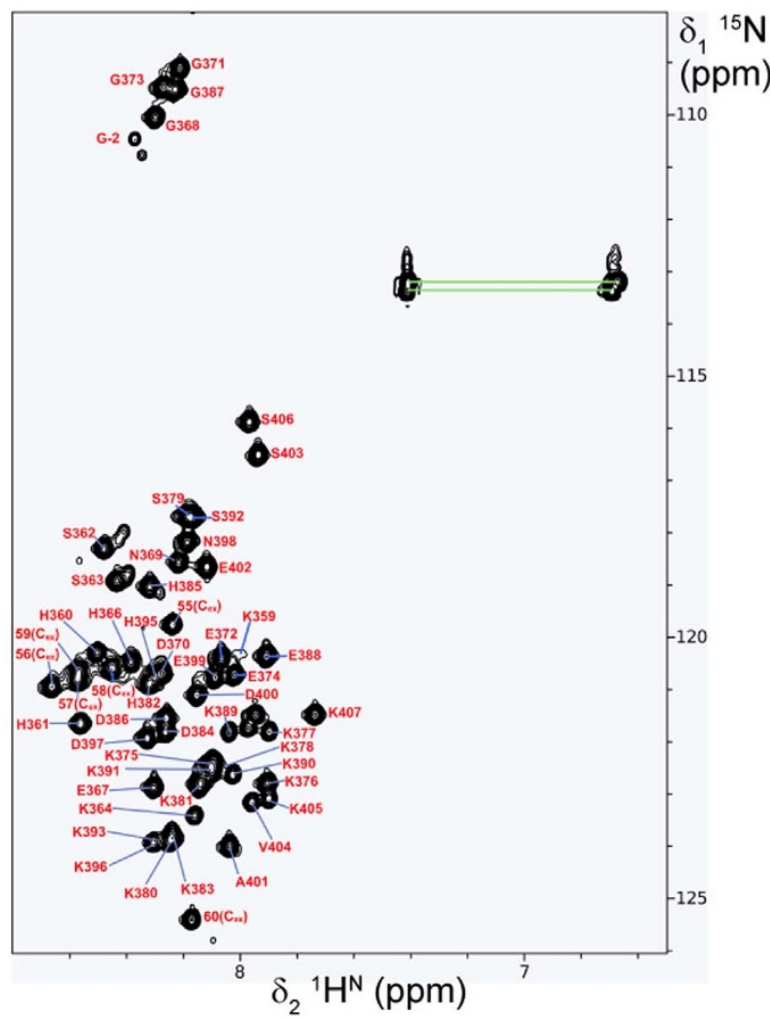

d

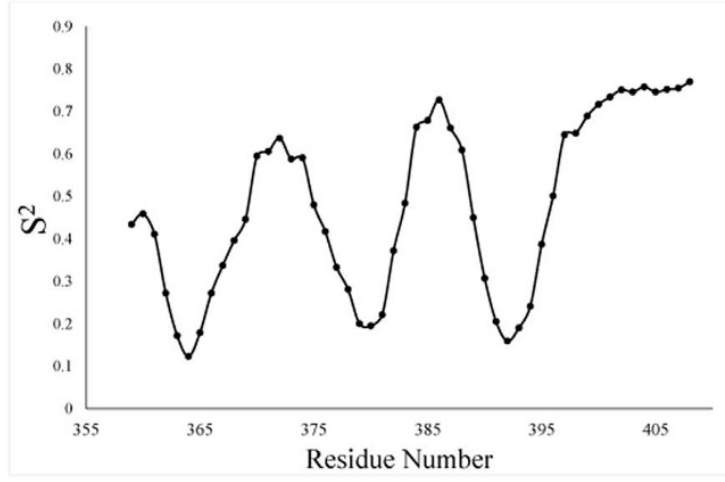

b

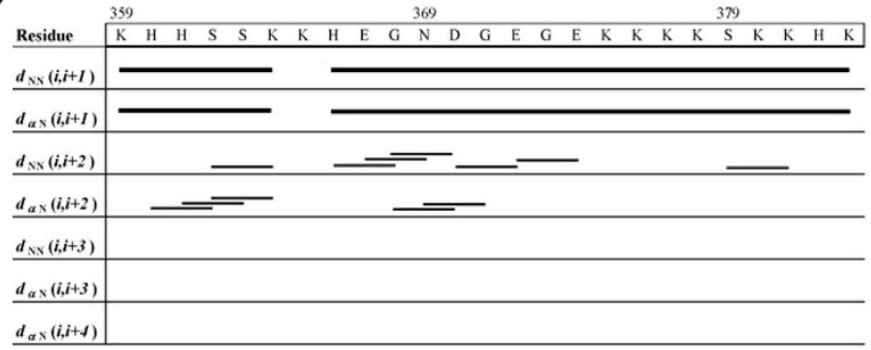

$\underline{d_{\alpha \times}(i, i+4)}$

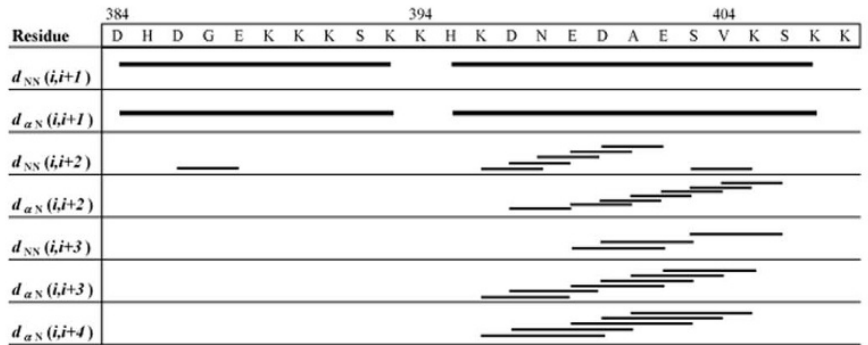

C

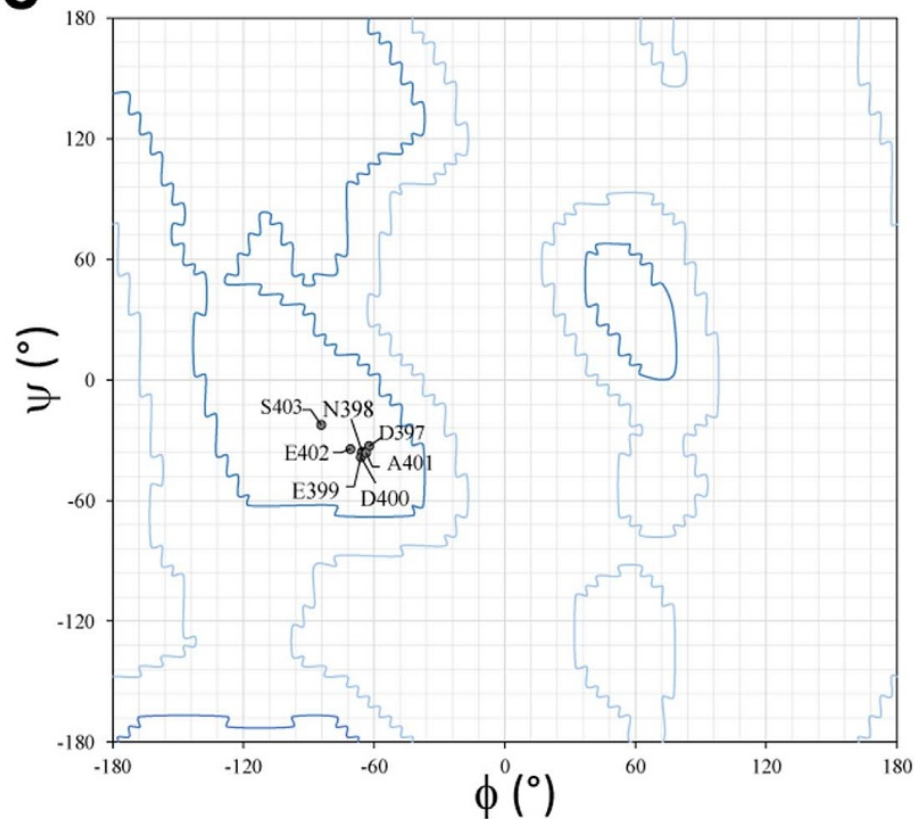

Figure $2 \mid$ Biophysical analyses of K2A1 in solution. (a) 2D $\left[{ }^{15} \mathrm{~N},{ }^{1} \mathrm{H}\right] \mathrm{HSQC}$ spectrum of K2A1 recorded at $278 \mathrm{~K}$ at pH 6.2 on a Bruker Avance III $500 \mathrm{MHz}$ spectrometer equipped with a cryogenic triple-resonance $5 \mathrm{~mm}$ TCI probe-head. Backbone amide resonance assignments are labeled. Resonances of extra residues derived from the plasmid vector on the C-terminus are labeled $\mathrm{C}_{\mathrm{ex}}$ in parentheses. (b) NOE connectivity plot for K2A1 showing sequential $(|\mathrm{i}-\mathrm{j}|=1)$ and short to medium range $(1<|\mathrm{i}-\mathrm{j}| \leq 4) \mathrm{H}^{\mathrm{N}}-\mathrm{H}^{\mathrm{N}}$ and $\mathrm{H}^{\mathrm{N}}-\mathrm{H}^{\alpha}$ connectivities. (c) Ramachandran plot for residues $\mathrm{D} 397$ to S403, exhibiting $\phi, \psi$ torsion angle values approximating to that of a right - handed helix. (d) Residue specific model-free backbone order parameter ( $\mathrm{S}^{2}$ ) values for K2A1 derived from observed chemical shifts showing backbone dynamics of K2A1.

disordered protein (IDP) at a physiological pH (Fig. 2b, Supplementary Fig. S3a). In a series of $2 \mathrm{D}\left[{ }^{15} \mathrm{~N},{ }^{1} \mathrm{H}\right]$ HSQC spectra measured for $\mathrm{K} 2 \mathrm{~A} 1$ from $278 \mathrm{~K}$ to $318 \mathrm{~K}$ in steps of $5 \mathrm{~K}$, the dispersion of ${ }^{1} \mathrm{H}^{\mathrm{N}}$ resonances increased with decrease in temperature. Lowering of temperature to $278 \mathrm{~K}$ also resulted in the appearance of several backbone amide resonances along with a small increase in the chemical shift dispersion and average peak intensity (Supplementary Fig. S3b,c). This could be attributed to a decrease in amide proton exchange rates, possible stabilization of local structural elements and a reduction of conformational exchange at lower temperatures. This behavior is unique to IDPs and unfolded proteins ${ }^{16}$ and is opposite of what is expected for a globular protein wherein lower temperatures reduce the molecular tumbling rate, causing line broadening due to fast transverse relaxation rates $\left(\mathrm{R}_{2}\right)$. Some studies have shown that IDPs have a propensity to form $\alpha$-helices at low temperatures and sample a smaller conformational space ${ }^{16-17}$. Interestingly, the $3 \mathrm{D}{ }^{15} \mathrm{~N}$-edited $\left[{ }^{1} \mathrm{H},{ }^{1} \mathrm{H}\right]$ NOESY strips of residues D397 to S406 showed a number of short to medium range $(1<|\mathrm{i}-\mathrm{j}|<4) \mathrm{H}^{\mathrm{N}}-\mathrm{H}^{\alpha}$ and $\mathrm{H}^{\mathrm{N}}-\mathrm{H}^{\mathrm{N}} \mathrm{NOEs}$ as compared to other residues in K2A1 (Supplementary Fig. S3d). Additionally, the backbone torsion angle values $(\varphi, \psi)$ of D397 to S403 as derived from TALOS + were found to fall in the region of the Ramachandran plot corresponding to a right-handed helix ${ }^{18}$ (Fig. 2c, Supplementary table S1), while the remainder were indicative of a backbone lacking in secondary structural elements.

We determined the backbone dynamics of $\mathrm{K} 2 \mathrm{~A} 1$ in terms of model-free order parameters $\left(S^{2}\right)$ from observed chemical shifts ${ }^{19}$, 
using TALOS + . The residue-wise backbone $S^{2}$ values showed three regions of high local mobility $\left(0 \leq S^{2} \leq 0.5\right)$ alternating with regions of relatively higher order $\left(0.5<\mathrm{S}^{2} \leq 1.0\right)$ along the length of the K2A1 polypeptide chain (Fig. $2 \mathrm{~d}$ ). The stretch of residues corresponding to the helix-like structural element was highly ordered $\left(0.6<S^{2} \leq 0.8\right)$ relative to the rest of the polypeptide. Sequence analysis of this particular stretch revealed that it has a higher hydrophobicity $(0.344 \pm 0.092)$ as compared to full length K2A1 (0.195 \pm $0.09)$. Given that past studies have linked side chain hydrophobicities to $\alpha$-helical propensity and stability ${ }^{20-22}$, we were able to conclude that a transient helix-like structure exists in this stretch, which is populated at lower temperatures due to reduction in conformational exchange rate.

K2A1 binds VARC in solution via four dynamic, positively charged, linear sequence motifs. In order to identify the interacting region on $\mathrm{K} 2 \mathrm{~A} 1$, it was next titrated against increasing VARC concentrations at $278 \mathrm{~K}$ and at very low ionic strengths $(0.013 \mathrm{M})$. The residues involved in the interaction between K2A1 and VARC were mapped (Fig. 3a,b) using the chemical shift perturbation (CSP) in backbone amide chemical shifts of K2A1 upon interaction with VARC. The line-widths in $2 \mathrm{D}\left[{ }^{15} \mathrm{~N},{ }^{1} \mathrm{H}\right]$ HSQC spectra of $\mathrm{K} 2 \mathrm{~A} 1$ remain constant up to a molar ratio of $1: 5$, indicating an initial moderate to weak binding in the fast exchange regime ${ }^{23}$. Line broadening was observed on saturation with VARC after a molar ratio of $1: 5$ up to a molar ratio of $1: 10$ (Supplementary Fig. S4a). This is possibly due to a cooperative increase in affinity between the two proteins leading to the formation of a large complex having a very fast transverse relaxation rate $\left(\mathrm{R}_{2}\right)^{24}$. No significant changes were observed in the control $2 \mathrm{D}\left[{ }^{15} \mathrm{~N},{ }^{1} \mathrm{H}\right]$ HSQC spectra of K2A1 titrated against increasing concentrations of bovine serum albumin (BSA) and human $\alpha$-synuclein, thus discounting crowding effects and nonspecific electrostatic interactions as contributing factors to chemical shift perturbation (Supplementary Fig. S4b,c). Amide chemical shift perturbation profile for the complex observed at $150 \mathrm{mM} \mathrm{NaCl}$ concentration (Supplementary Fig. S5) indicated the stability of the complex at a physiological salt concentration. However few residues showed small chemical shift perturbations and changes in amide line widths as compared to the complex at $0 \mathrm{mM} \mathrm{NaCl}$, indicative of possible changes in exchange rate, while bulk K2A1 remains in the VARC-bound state. The spectra of the complex at no salt were used for further analysis as they had better line-widths.

Residues H360, H361, K378, H382, K390, K405 and S406 showed higher CSPs (greater than one standard deviation from the mean) relative to other residues and are likely to be involved in the interaction (Fig. 3b). Lysine ( $\mathrm{pI}=9.74)$ and histidine $(\mathrm{pI}=7.59)$ residues have a net positive charge at $\mathrm{pH} 6.2$ and hence, are most likely to interact with acidic residues on VARC. A global observation of the perturbation profile showed four distinct regions on the K2A1 polypeptide (K359-D370 (region 1), G373-E388 (region 2), K390-D400 (region 3) and A401-K407 (region 4)) that are involved in the interaction.

An interesting correlation was observed between CSPs, sequence specific charge and order parameter $\left(\mathrm{S}^{2}\right)$ of $\mathrm{K} 2 \mathrm{~A} 1$. Regions experiencing higher CSPs have net positive charge and are more flexible (low values of $S^{2}$ ) (Fig. 3c). All four interacting regions showed a significant $(p<0.05)$ positive correlation between CSPs and charge and a significant $(p<0.05)$ negative correlation between CSPs and $S^{2}$ (Supplementary table S2). Barring region 4 , all regions also showed a significant $(p<0.05)$ negative correlation between charge and $S^{2}$. The direct implication of these observations was that the probability of a residue on $\mathrm{K} 2 \mathrm{~A} 1$ binding to VARC depends on its charge, the charge distribution in its immediate neighborhood and the local backbone dynamics. For instance, the tetra-lysine stretch from K375 to K378, showed a gradually increasing CSP from K375 to $\mathrm{K} 378$, rather than equal values for all four residues. This is partially due to the presence of a negatively charged stretch of amino acids (D370 to E374) at the N-terminal of K375 that conferred an effective charge of +0.2 on K375. Such instances of 'nearest-neighbor' effects were also observed for several serine residues that showed higher CSPs compared to other serines, owing to their being sandwiched between lysine residues (K378-S379-K380, K391-S392-K393 and K405-S406-K407). It might be possible that serines also contribute to binding by forming $\mathrm{H}$-bonds.

Regions 1, 2 and 3 showed more backbone flexibility at their centers as compared to their respective edges, which would likely aid in their electrostatic binding to VARC by allowing a wider range of conformational sampling with exchanges occurring at sub-microsecond time-scales. These three regions would therefore, resemble 'cationic clouds' in solution, bridged by relatively less mobile negatively charged stretches. However, region 4 showed the largest CSPs despite being the most rigid segment of $\mathrm{K} 2 \mathrm{~A} 1$, indicating a possible role of the transiently structured region (D397-S403) in enhancing binding affinity.

In contrast to free $\mathrm{K} 2 \mathrm{~A} 1$, dispersion of backbone amide proton chemical shift did not increase for the complex (Supplementary Fig. S6). On the contrary, the dispersion decreased at molar concentrations of VARC exceeding that of K2A1, reaching a minima of $\sim 0.7 \mathrm{ppm}$ after a molar ratio of 1:5 (K2A1 to VARC). Since backbone amide proton chemical shift dispersion is a sensitive measure of secondary structures in IDPs ${ }^{25}$, one can assume that little or no disorder-to-order transition occurs for K2A1 upon binding to VARC. Instead, the partially structured state that was observed for K2A1 at $278 \mathrm{~K}$ was lost upon binding and it had the signature of a more coil-like global configuration. This departure from the classical 'folding upon binding' paradigm has been recently explored in cases of complexes involving IDPs and globular proteins with disordered regions and membrane proteins ${ }^{26}$. Moreover, several interactions between IDP pairs have also been found to remain disordered upon binding ${ }^{27-29}$.

The observation of chemical shift perturbations upon titrating K2A1 against VARC necessitated the quantification of the strength of the interaction. We extracted dissociation constants for all residues that showed backbone amide perturbations greater than one standard deviation from the mean. Of these, fitted curves and dissociation constants of K378, H382, K390, K405 and S406 are shown as representatives (Fig. 4a, Supplementary Table S3). Within the limits of experimental error, the values for these residues were found to range between 7 and $15 \mu \mathrm{M}$ that is in agreement with previously reported values ${ }^{14}$. We performed isothermal titration calorimetry (ITC) by titrating VARC against K2A1 at $298 \mathrm{~K}$ in a buffer of minimal ionic strength $(0.013 \mathrm{M})$, so as to be able to observe the minutest of electrostatic interactions between oppositely charged species, as also to minimize charge shielding of amino acids by buffer counter ions. The $\mathrm{pH}$ of the interaction was buffered at 6.9 as the charge difference between $\mathrm{K} 2 \mathrm{~A} 1$ and VARC is likely to be highest at intermediate $\mathrm{pH}$ values between their respective theoretical isoelectric points (9.66 and 4.85, respectively). Assuming that four similar negatively charged regions on VARC would match the four interacting regions on $\mathrm{K} 2 \mathrm{~A} 1$, we fitted the ITC thermogram to a four site-binding model (Figure 4b). While the net stoichiometry of K2A1 and VARC in the complex remains unclear, the dissociation constants obtained from ITC are in agreement with those obtained for strongly interacting residues on $\mathrm{K} 2 \mathrm{~A} 1$. These values are similar to values reported in an earlier study, which had shown that full length $\mathrm{K} 2 \mathrm{~A}$ binds to various subdomains of VARC with $\mathrm{K}_{\mathrm{d}}$ values ranging from 1.5 to $32 \mu \mathrm{M}^{14}$. The average dissociation constant for the reaction was found to be $32.06 \mu \mathrm{M}$, indicative of a moderate to weak affinity binding as a whole, consistent with the narrow resonances obtained in the initial titration steps carried out using NMR.

KAHRP and PfEMP1 co-localize in membrane knobs. Previous in vivo studies have independently localized KAHRP and PfEMP1 to 

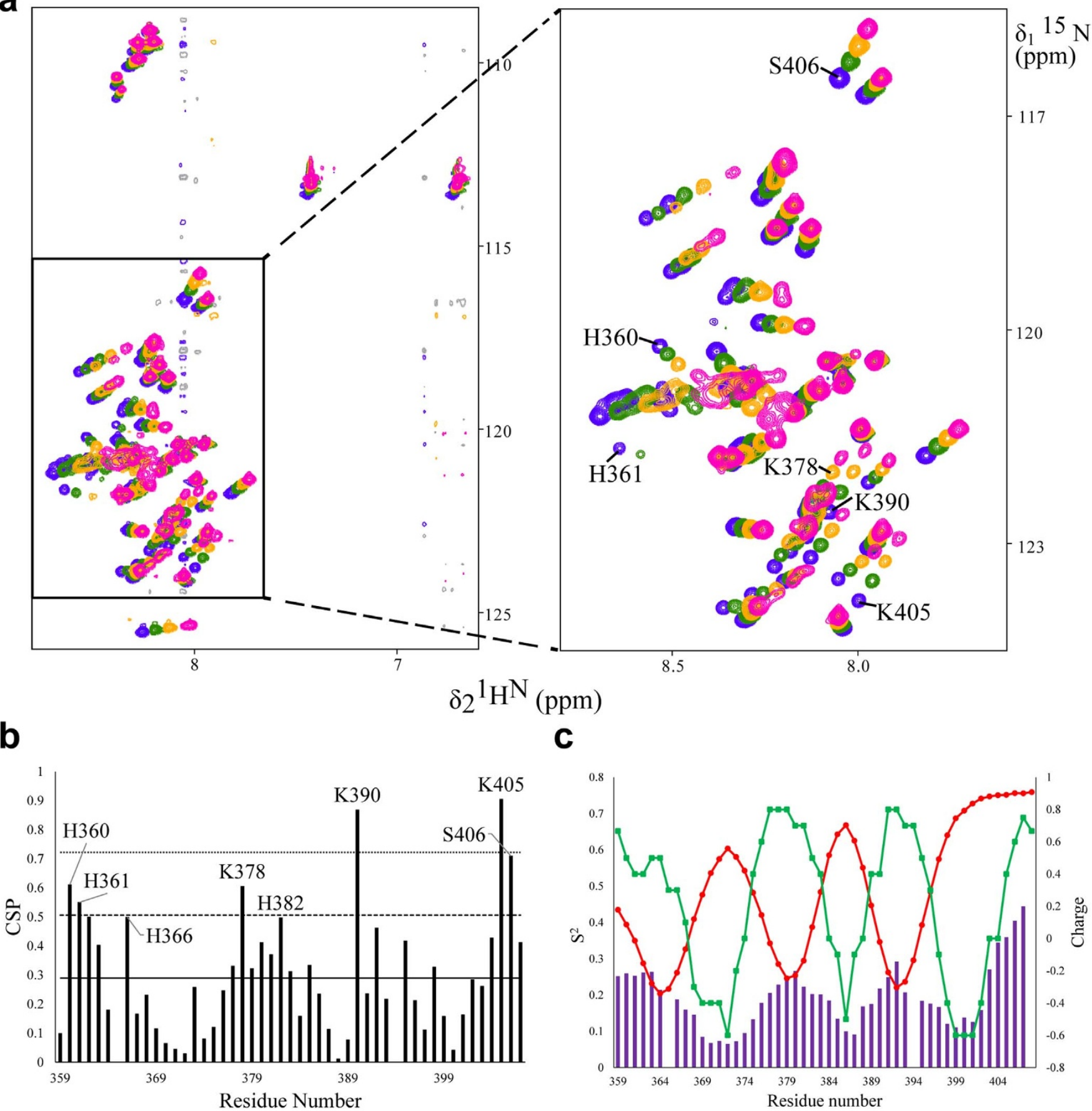

Figure 3 K2A1-VARC interaction in solution. (a) Overlay of $2 \mathrm{D}\left[{ }^{15} \mathrm{~N},{ }^{1} \mathrm{H}\right]$ HSQC spectra of free K2A1 (blue) versus $1: 1$ (green), $1: 2.5$ (ochre) and $1: 5$ (pink) molar ratios of ${ }^{15} \mathrm{~N}$-labeled K2A1 to unlabeled VARC. Demarcated residues are those undergoing significant perturbation. $(\mathrm{b}){ }^{1} \mathrm{H}^{\mathrm{N}}$ and ${ }^{15} \mathrm{~N}$ CSPs for K2A1 upon binding to 5 molar equivalents of VARC. The horizontal lines represent the mean (-), mean plus one standard deviation (--) and mean plus two standard deviations (....). (c) Comparison of perturbation, charge and $\mathrm{S}^{2}$. Overlay of chemical shift perturbations of K2A1 on addition of VARC (purple bars), backbone order parameter $\mathrm{S}^{2}$ of free K2A1 (red dots) and charge profile of free K2A1 (green squares). All data were smoothed using a moving average of 5 to account for nearest neighbor effects. Correlations between the variables are given in Supplementary table S2.

knobs using polyclonal antibodies raised against the full-length proteins $s^{7,10,11,30}$. However, a simultaneous probing of the two proteins has been lacking to date. In order to investigate the physical association of KAHRP and VARC inside the infected RBCs we used anti-K2A1 and anti-VARC antibodies to visualize KAHRP and PfEMP1. Interestingly, confocal laser scanning microscopy (CLSM) of $P$. falciparum infected erythrocytes showed the co-localization of KAHRP and PfEMP1 to the erythrocyte membrane (Fig. 5a, b). The co-localization was seen in several trophozoite infected RBCs, including early stage trophozoites with little hemozoin. No fluorescence was observed in the uninfected erythrocyte controls, eliminating cross-reactivity of the antibodies with erythrocyte components.

The degree of co-localization of the two fluorophores AlexaFluor488 and AlexaFluor594 are explained using Pearson's correlation and its coefficients $\mathrm{c} 1$ and $\mathrm{c}^{31}$ (Supplementary table S4).

By combining the sensitive technique of fluorescence and the resolution offered by confocal laser scanning microscopy, an accur- 
a

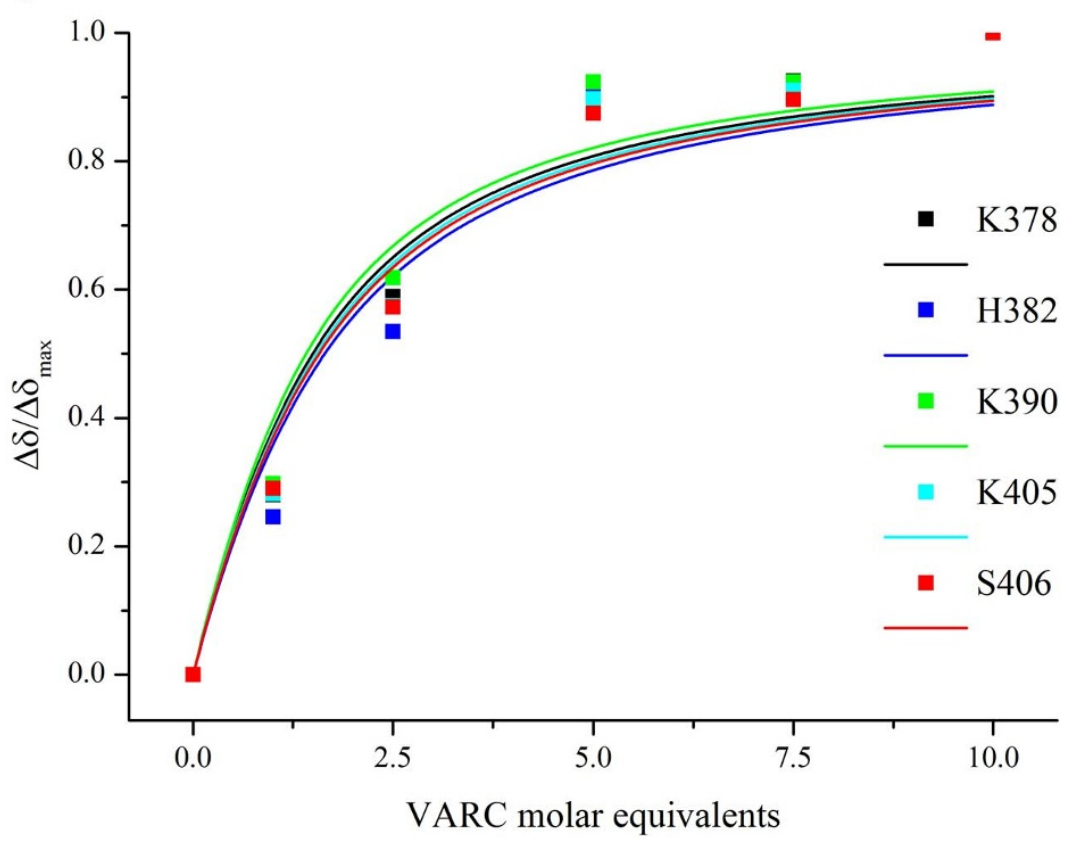

Time ( $\min )$

b $\quad \begin{array}{rllllllllllll}-10 & 0 & 10 & 20 & 30 & 40 & 50 & 60 & 70 & 80 & 90 & 100 & 110\end{array}$

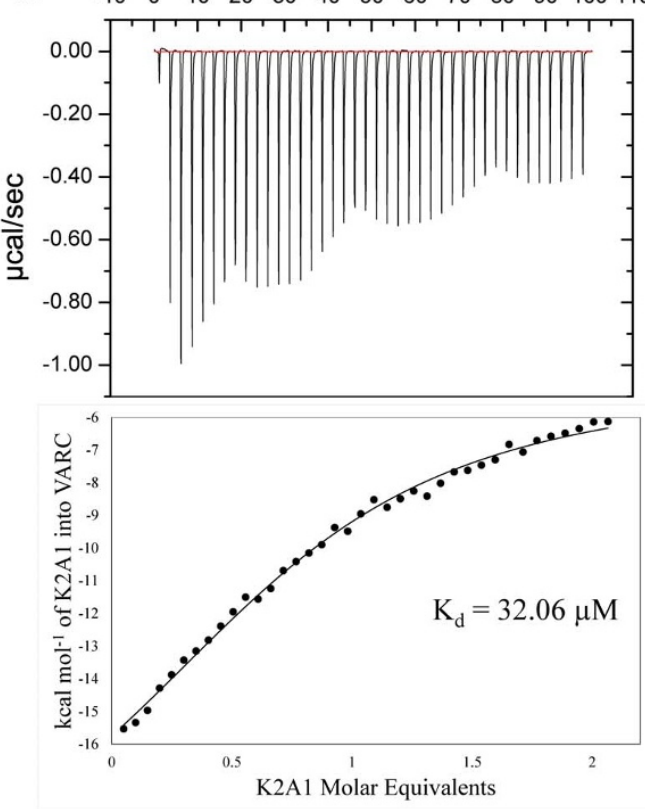

Figure $4 \mid$ Binding affinities within the K2A1-VARC complex. (a) Non-linear least squares fit to eq. 4 of five resonances each for five representative residues having CSPs higher than mean plus $1 \sigma$. Dissociation constants and fitting statistics are tabulated in Supplementary table S3. (b) ITC isotherm of K2A1 binding on VARC. (Kd values for a four-site binding were $9.8 \mu \mathrm{M}, 10.3 \mu \mathrm{M}, 10.1 \mu \mathrm{M}$ and 9.6 $\mu \mathrm{M}$. Apparent global Kd was $32.06 \mu \mathrm{M}$.)

ate measurement of co-localization could be made by statistically determining the degree of overlap between the fluorophores. As the Pearson's correlation fell between $0.6-0.8$, it could be assumed that the localization of KAHRP (green) and PfEMP1 (red) was not completely mutually inclusive. This was because the export of PfEMP1 to the erythrocyte membrane is not dependent solely on KAHRP $^{30,32}$. However, in regions where co-localization did occur, the coefficients $c 1$ and $c 2$ were in the range $0.97-1.0$, implying a near perfect overlap at the optical resolution being used. Together with the NMR and calorimetric titration these immunofluorescence studies provide an in vivo evidence of co-localization of KAHRP and PfEMP1 (VARC) at the erythrocyte membrane.

\section{Discussion}

The interactions between several parasite proteins that govern the related phenomena of knob formation and cytoadherence of $P$. falciparum infected erythrocytes (iRBCs) to endothelial cells have been extensively studied to date. Previous studies have shown that the knob associated histidine rich protein (KAHRP) is indispensable to knob formation in iRBCs ${ }^{10-11}$ and that mutant parasites with the KAHRP gene knocked out are unable to adhere to vascular endothelium under the shear stress imposed by physiological flow conditions $s^{9,33}$. Moreover, despite binding to the spectrin-actin junction of the erythrocyte cytoskeleton with a high affinity via its cytoplasmic domain, PfEMP1 requires KAHRP for additional stability ${ }^{34-35}$. Membrane expression of PfEMP1 is also impaired in $\mathrm{KAHRP}^{-}$ mutants, implying a role of KAHRP in recruitment of PfEMP1 molecules also ${ }^{9,32}$. Recent studies using immobilized protein assays have delineated the interaction between domains of KAHRP and PfEMP1 $1^{13-14,36}$ to show that the central lysine rich repeat region of KAHRP, termed K2A, interacts with VARC with a moderate affinity electrostatic binding ${ }^{15}$. However, the absence of any detectable
DAPI

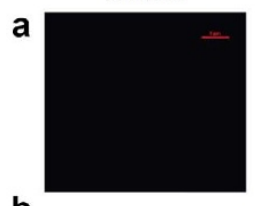

b

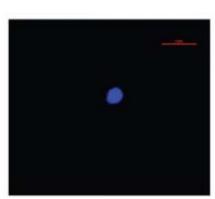

KAHRP
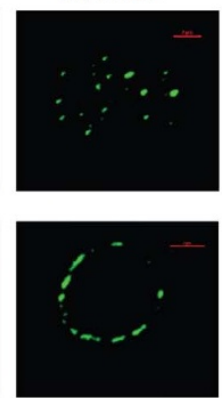

PfEMP1
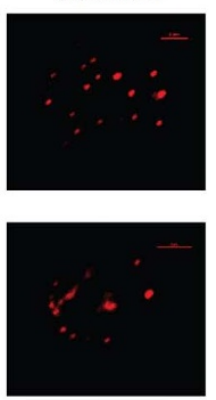

MERGE
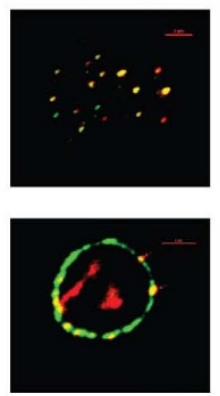

\section{OVERLAY}
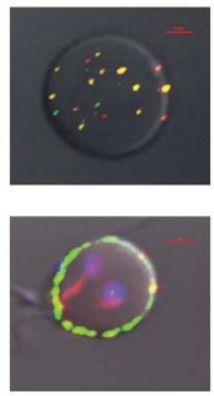

Figure 5 Immunofluorescence based co-localization of KAHRP (using anti-K2A1 antibodies) and PfEMP1 (using anti-VARC antibodies) in $P$. falciparum infected erythrocytes. Confocal laser scanning microscopy images of iRBCs showing individual images of DAPI stained parasite nuclei (blue), KAHRP (green), PfEMP1 (red), merged images of KAHRP and PfEMP1 and an overlay of the above on a DIC (differential interference contrast) image of the iRBC. Co-localizations are seen in yellow (red arrows). The red bar in each image corresponds to a scale of $2 \mu \mathrm{m}$. (a) Optical slice of the plasma membrane of a trophozoite infected RBC, showing extensive co-localization. (b) Cross-section of a trophozoite-infected RBC exhibiting co-localization on RBC membrane. 
binding of these two domains in solution has been speculated upon in a recent study ${ }^{37}$. Our findings constitute the first report of the interaction between $\mathrm{K} 2 \mathrm{~A}$ and VARC in solution and its structural implications in the localization of PfEMP1 to knobs, using a combination of solution-state nuclear magnetic resonance spectroscopy, calorimetry and microscopic techniques.

$\mathrm{K} 2 \mathrm{~A}$ domain contains repeats of charged residues and is predicted to be a highly disordered domain ${ }^{38}$. Analysis of the $2 \mathrm{D}\left[{ }^{15} \mathrm{~N},{ }^{1} \mathrm{H}\right]$ HSQC spectrum of K2A, along with its abnormal electrophoretic migration patterns and presence of highly positively charged low complexity regions revealed it to be an intrinsically disordered protein (IDP) at physiological pH. VARC on the other hand, possesses a structured $\alpha$-helical core surrounded by regions of high intrinsic disorder that shows little or no propensity for secondary structure formation under physiological conditions ${ }^{37}$.

Consolidation of data obtained from solution NMR studies and calorimetry enable us to arrive at a consensus model for the K2A1VARC interaction and its implication in the tethering of PfEMP1 to membrane knobs. Long-range electrostatic attractive forces between four positively charged linear sequence motifs on K2A1 and anionic patches on VARC initiate complex formation. The inherent dynamism of the first three form 'cationic clouds' on $\mathrm{K} 2 \mathrm{~A} 1$ that provide the conformational variability required to increase chances of attaining binding favorable states. The binding of these three regions probably leads to loss of transient structural elements on K2A1, causing it to attain an extended coil-like configuration on the VARC surface. This frees the more rigid region 4 to participate in a final binding step. Given the line broadening observed on saturating K2A1 with VARC, the binding of $\mathrm{K} 2 \mathrm{~A} 1$ to VARC most likely undergoes a cooperative increase in affinity followed by a finite oligomerization till a larger structure is formed. The oligomerization process is likely to be driven by ionic cross-linking mediated by $\mathrm{K} 2 \mathrm{~A} 1$, which, in vivo, would cause the characteristic clustering of PfEMP1 on knobs. However, the four focal points of association are at best, held together by a moderate affinity interaction, resulting in a dynamic equilibrium between bound and unbound states. Such 'fuzzy complexes' have been described previously using the polyelectrostatic model, wherein multiple linear binding motifs constitute a dynamic ensemble of binding sites on a relatively ordered interacting partner ${ }^{39}$. However, the KAHRP-VARC complex as a whole may not be completely disordered and dynamic in vivo, in light of a recent finding ${ }^{40}$ that has shown the localization of a parasite encoded chaperone protein KAHsp40 to knobs, which may be instrumental in the stabilization and folding of the IDPs present therein.

In conclusion, the study of the phenomenon of cytoadherence has been hampered by the lack of biophysical and structural information on the macromolecular complexes that make up the knob. Given the presence of several low-complexity and unstructured regions in its constituent proteins, these complexes are not amenable to conventional methods of determining atomic resolution structures. Our study of the interaction between K2A1 and VARC corroborate the data previously available through immobilized assays ${ }^{13-14,36}$ and also provided a more detailed understanding of the mechanism of PfEMP1 tethering to membrane knobs. Based on evidence gathered from solution NMR and calorimetry we were able to conclude that $\mathrm{K} 2 \mathrm{~A} 1$ interacts with VARC in solution via four positively charged dynamic binding regions to form a disordered and dynamic complex. Oligomerization of this complex is probably due to cross-linking mediated by $\mathrm{K} 2 \mathrm{~A} 1$ forming the basis of accumulation of PfEMP1 molecules on knobs. The electrostatic nature of this interaction is largely due to long-range attractive forces between positively charged lysine and histidine residues on K2A1 and acidic residues on VARC. This knowledge would be indispensable in the screening of small molecules such as halogenated derivatives of lysine and histidine or cationic peptides that may be used to disrupt knob association of PfEMP1. From an in vivo point of view, the complex formation was put in perspective by our demonstration of the subcellular colocalization of the full-length proteins KAHRP and PfEMP1 in erythrocytes infected with trophozoite-stage $P$. falciparum. Our study thus provides a molecular glimpse into the tethering of PfEMP1 to knobs by KAHRP and may act as a seed for more detailed structural studies involving other domains of KAHRP, VARC and the erythrocyte cytoskeleton.

\section{Methods}

Molecular cloning and sequence analysis of VARC, K2A and K2A1. Expression clones of VARC domain of PfEMP1 (7399-8271 bp) encoding for amino acids 24672757 and the K2A domain of KAHRP (1075-1341 bp) encoding for amino acids 359 447 were obtained as a kind gift from Dr. Amit Sharma. Both were cloned in pET28b vector. The DNA fragment corresponding to K2A1 (1075-1224 bp of KAHRP, amino acid residues 359-408) was PCR amplified from the pET28b-K2A vector construct. The major amplification product of 177 base pairs was cloned into pET28b vector along with a C-terminal hexa-Histidine tag. The clonings were confirmed by DNA sequencing (Macrogen, Inc., Seoul, South Korea). The vector constructs were used to transform Escherichia coli BL21 (DE3) CodonPlus cells for protein overexpression. Phusion polymerase, restriction enzymes and T4 DNA Ligase were purchased from New England Biolabs. The plasmid vector pET28b and E. coli BL21 (DE3) CodonPlus cells were obtained from Novagen.

The theoretical isoelectric $\mathrm{pH}$ values of the proteins were determined using the 'ProtParam' tool on the ExPASy ${ }^{41}$ web server (http://web.expasy.org/protparam). Hydrophobicities were calculated using Kyte and Doolittle method ${ }^{42}$ in the 'ProtScale' tool (http://web.expasy.org/protscale/) with a window of 5 amino acids, normalized to values between 0 and 1 . Residue level charge and net protein charge were calculated using the 'charge' tool on the EMBOSS web server (http://emboss.bioinformatics.nl), wherein lysine and arginine are assigned a net charge of +1 each; histidine, a net charge of +0.5 and aspartate and glutamate are each assigned a net charge of -1 at $\mathrm{pH}$ 7.0. The remaining amino acids are assigned a net charge of zero.

Protein preparation and generation of antibodies. Unlabeled, uniformly ${ }^{15} \mathrm{~N}$ labeled and $\left[{ }^{15} \mathrm{~N},{ }^{13} \mathrm{C}\right]$-labeled $\mathrm{K} 2 \mathrm{~A}$ and $\mathrm{K} 2 \mathrm{~A} 1$ were over-expressed in $E$. coli BL21(DE3) CodonPlus strain in M9 minimal media containing ${ }^{15} \mathrm{NH}_{4} \mathrm{Cl}$ and ${ }^{13} \mathrm{C}$ glucose as the sole nitrogen and carbon sources respectively. Unlabeled VARC was similarly over-expressed in Luria-Bertani medium (USB chemicals). The recombinant proteins were expressed in soluble form. All protein purifications were carried out using Qiagen Ni-nitrilo triacetic acid (Ni-NTA) gravity flow columns, followed by gel permeation chromatography (GPC) on a GE 16/60 HiLoad Superdex 75 column to obtain samples of approximately $>95 \%$ homogeneity. Sample purity was checked on SDS-PAGE gels. Eluted fractions were concentrated using centrifugal filters (Molecular weight cut-off of $3 \mathrm{kDa}$ ). K2A and K2A1 were concentrated up to 5-6 $\mathrm{mg} / \mathrm{ml}(0.5-0.9 \mathrm{mM}$ for $\mathrm{K} 2 \mathrm{~A} 1$ and $\mathrm{K} 2 \mathrm{~A})$ while VARC was concentrated up to 1$2 \mathrm{mg} / \mathrm{ml}(0.05-0.07 \mathrm{mM})$. Given the absence of aromatic residues in K2A1, bicinchoninic acid test $\left(\text { at } 40^{\circ} \mathrm{C}\right)^{43}$ validated by PULCON NMR technique ${ }^{44,45}$ were employed to determine the protein concentration. Protease inhibitor cocktails (Roche) and pepstatin were added in all protein preparations to prevent proteolytic degradation. Final preparations were divided into aliquots, flash frozen in liquid nitrogen and stored at $-20^{\circ} \mathrm{C}$. Given the high sensitivity to proteolysis for VARC, fresh aliquots were used for each experiment, with no more than one freeze/thaw cycle.

Generation of antibodies was carried out in rabbit (VARC) and mouse (K2A1) immunized against $90-95 \%$ pure protein samples. Polyclonal antibodies (IgG) specific for the respective protein were purified from antisera by antigen affinity chromatography and used for immunofluorescence experiments. Antibody preparations were procured from Bangalore Genei, India.

NMR sample preparation. K2A1 sample was prepared for NMR using protein preparations concentrated to $0.5-0.7 \mathrm{mM}$ in $10 \mathrm{mM}$ sodium phosphate buffer, $\mathrm{pH}$ 6.2 , containing $50 \mathrm{mM} \mathrm{NaCl}, 5 \mathrm{mM}$ DTT, $5 \% \mathrm{D}_{2} \mathrm{O}(v / v)$ and $0.01 \% \mathrm{NaN}_{3}(w / v)$. NMR titrations of K2A1 against VARC were carried out in $10 \mathrm{mM}$ sodium phosphate buffer, $\mathrm{pH} 6.2$, containing $5 \mathrm{mM} \mathrm{DTT}, 5 \% \mathrm{D}_{2} \mathrm{O}(v / v)$ and $0.01 \% \mathrm{NaN}_{3}(w / v)$, without any additional salts. Samples also contained protease inhibitor cocktails (Roche) and pepstatin. Traces of 4,4-dimethyl-4-silapentane-1-sulfonic acid (DSS) were added as an internal reference.

NMR data acquisition, processing and analysis. All experiments were carried out on Bruker Avance III spectrometers equipped with $5 \mathrm{~mm}$ cryogenic triple-resonance TCI probes, operating at field strengths ( ${ }^{1} \mathrm{H}$ Larmor frequency) of 500 and $700 \mathrm{MHz}$. Temperature optimization of backbone ${ }^{1} \mathrm{H}^{\mathrm{N}}$ chemical shift dispersion and resonance line-widths was carried out by acquiring a series of $2 \mathrm{D}\left[{ }^{15} \mathrm{~N},{ }^{1} \mathrm{H}\right]$ HSQC spectra at temperatures varying from $278 \mathrm{~K}$ to $318 \mathrm{~K}$, in steps of $5 \mathrm{~K}$. For the purpose of resonance assignments, a set of standard double and triple resonance spectra namely 2D $\left[{ }^{15} \mathrm{~N},{ }^{1} \mathrm{H}\right]$-HSQC, 2D ${ }^{13} \mathrm{C}^{\prime}$-detected NCO, 2D ${ }^{13} \mathrm{C}^{\prime}$-detected CACO, 3D HNCA, 3D CBCAcoNH, 3D HNCACB, 3D HNCO, 3D CcccoNH, 3D HcccoNH, $2 \mathrm{D}\left[{ }^{13} \mathrm{C},{ }^{1} \mathrm{H}\right]-$ HSQC, 3D ${ }^{15} \mathrm{~N}$-edited $\left[{ }^{1} \mathrm{H},{ }^{1} \mathrm{H}\right]$-NOESY and $3 \mathrm{D}^{13} \mathrm{C}$-edited $\left[{ }^{1} \mathrm{H},{ }^{1} \mathrm{H}\right]$-NOESY (NOESY mixing time: $100 \mathrm{~ms}$ ) were measured at $278 \mathrm{~K}$. Topspin 2.1 (Bruker AG) software was used for acquisition, Fourier transformation and processing of time-domain data ${ }^{13} \mathrm{C}$ and ${ }^{15} \mathrm{~N}$ shifts referenced indirectly to the DSS methyl proton resonance at $0 \mathrm{ppm}$ 
in all spectra. Backbone and side-chain resonances were assigned manually using Computer Aided Resonance Assignment (CARA $)^{46}$. Automated NOE peak assignment and chemical shift validation were carried out using UNIO ' $10^{47,48}$ Calculation of torsion angle dynamics and distance geometries was attempted by simulated annealing of 10,000 steps in CYANA 3.0 using 7 iterative cycles. Dihedral angle values $(\varphi, \psi)$ and model-free order parameters $\left(S^{2}\right)$ were derived from observed chemical shifts using TALOS $+{ }^{19,49}$ (http://spin.niddk.nih.gov/bax/nmrserver/talos/).

NMR titrations of K2A1 against VARC. A series of 2D $\left[{ }^{15} \mathrm{~N},{ }^{1} \mathrm{H}\right]$ HSQC spectra of ${ }^{15} \mathrm{~N}$-labeled K2A1 were acquired at $278 \mathrm{~K}$ with an increasing concentration of unlabeled VARC up to saturation. $1: 1,1: 2.5,1: 5,1: 7.5$ and $1: 10$ molar ratios of $\mathrm{K} 2 \mathrm{~A} 1$ to VARC were used. K2A1 concentration was reduced to $10 \mu \mathrm{M}$ to accommodate the higher (up to $1: 10$ ) molar ratios, given that VARC could be concentrated to a maximum of $3.4 \mathrm{mg} / \mathrm{ml}(100 \mu \mathrm{M})$ without aggregation. Correspondingly, number of scans used in the $2 \mathrm{D}\left[{ }^{15} \mathrm{~N},{ }^{1} \mathrm{H}\right] \mathrm{HSQC}$ spectra was increased to 512 to obtain good signal-to-noise. We measured a series of $2 \mathrm{D}\left[{ }^{15} \mathrm{~N},{ }^{1} \mathrm{H}\right]$ HSQC spectra of the 1:5 K2A1-VARC complex at $20 \mathrm{mM}, 50 \mathrm{mM}, 100 \mathrm{mM}$ and $150 \mathrm{mM} \mathrm{NaCl}$ to test the stability of the complex under higher ionic strengths. As controls, ${ }^{15} \mathrm{~N}$-labeled K2A1 was titrated against bovine serum albumin and human $\alpha$ synuclein $(1: 0.5,1: 1,1: 2$ and $1: 5$ molar ratios). Integrity of the sample was verified before and after each acquisition using SDS-PAGE. Owing to the proteolytic degradation of VARC after 4-5 hours in solution, we were unable to acquire lengthy triple resonance spectra or obtain dynamics information for K2A1 in the bound form. Perturbation in the backbone amide ${ }^{1} \mathrm{H}^{\mathrm{N}}$ and ${ }^{15} \mathrm{~N}$ chemical shifts $(\Delta \delta)$ was calculated using the formula

$$
\Delta \delta_{15 N^{H}, H^{N}}=\sqrt{\left(\frac{\Delta \delta_{15} N^{H}}{5}\right)^{2}+\left(\Delta \delta_{H^{N}}\right)^{2}}
$$

Where $\Delta \delta\left({ }^{1} \mathrm{H}^{\mathrm{N}}\right)$ and $\Delta \delta\left({ }^{15} \mathrm{~N}\right)$ are the changes in backbone amide chemical shifts for ${ }^{1} \mathrm{H}^{\mathrm{N}}$ and ${ }^{15} \mathrm{~N}$ respectively, from free K2A1. CSPs for each residue were calculated for $1: 1,1: 2.5$ and $1: 5$ molar ratios of K2A1 to VARC. Higher molar ratios $(1: 7.5$ and $1: 10$ ) had missing resonances in their HSQC spectra due to line broadening and were not included.

Pearson correlation coefficients between perturbations, charge and $S^{2}$ (referred to as variables for simplicity) were calculated using a moving average with a window of 5 amino acids for each of the three variables, to account for nearest neighbor effects. The averaged value $\left(\bar{x}_{n}\right)$ of a variable $x\left(\mathrm{CSP}\right.$, charge or $\left.\mathrm{S}^{2}\right)$ for the $n$th residue was calculated as:

$$
\bar{x}_{n}=\frac{1}{5} \sum_{i=n-2}^{n+2} x_{i}
$$

The Pearson correlation coefficients $\left(\mathrm{r}_{\mathrm{x}, \mathrm{y}}\right)$ were computed using the formula:

$$
r_{x y}=\frac{\sum\left(\bar{x}_{n}-\bar{x}\right)\left(\bar{y}_{n}-\bar{y}\right)}{\sqrt{\sum\left(\bar{x}_{n}-\bar{x}\right)^{2} \sum\left(\bar{y}_{n}-\bar{y}\right)^{2}}}
$$

Where $\bar{x}_{n}$ and $\bar{y}_{n}$ are averaged values of two variables $x$ and $y$ for the $n$th residue as calculated using eq. 2 while $\bar{x}$ and $\bar{y}$ are the means of the corresponding variables across the entire range of residues being tested. The $P$-values for correlation coefficients were derived at a $95 \%$ confidence level using $n-2$ degrees of freedom. Dissociation constants were derived from amide chemical shift perturbation values ${ }^{50}$ by non-linear least squares fitting of five resonances to the equation

$$
\frac{\Delta \delta}{\Delta \delta_{\max }}=0.5\left[\left(1+\frac{K_{d}}{C_{p}}+M\right)-\sqrt{\left(\left(1+\frac{K_{d}}{C_{p}}+M\right)^{2}-4 M\right)}\right]
$$

Where $\Delta \delta$ is the normalized amide chemical shift perturbation calculated in eq. 1, $\Delta \delta_{\text {max }}$ is the normalized amide chemical shift perturbation between free and VARC saturated $\mathrm{K} 2 \mathrm{~A} 1, \mathrm{~K}_{\mathrm{d}}$ is the dissociation constant, $\mathrm{C}_{\mathrm{p}}$ is the concentration of labeled $\mathrm{K} 2 \mathrm{~A} 1(10 \mu \mathrm{M})$ and $\mathrm{M}$ is the molar ratio of VARC to K2A1. All calculations and plotting of graphs were carried out using OriginPro v8.6, SigmaPlot v12 and Microsoft Excel 2013.

Isothermal titration calorimetry. Isothermal titrations of VARC against $\mathrm{K} 2 \mathrm{~A} 1$ were performed on a GE MicroCal ITC $_{200}$ calorimeter to obtain thermodynamic parameters of the interaction. Both proteins were prepared for titration by extensively dialysing against $10 \mathrm{mM}$ sodium phosphate buffer, $\mathrm{pH} 6.9$ containing $5 \mathrm{mM}$ DTT, without any additional salts. $0.7 \mathrm{mM} \mathrm{K} 2 \mathrm{~A} 1$ was used as the syringe solution and $0.07 \mathrm{mM}$ VARC was added to the ITC cell. Dilution effects were negated by titrating K2A1 against the buffer solution and subtracting the resultant isotherm from the experimental data. The titrations were carried out at $298 \mathrm{~K}$ over 40 injections of $1 \mu \mathrm{L}$ each, with a time gap of $240 \mathrm{~s}$ between each injection, with constant stirring at $1000 \mathrm{rpm}$ to ensure homogenous mixing. Data analyses and peak integration were carried out using Origin 7 software. To obtain a binding model consistent with the four binding regions of K2A1, heats were fitted to a sequential four site model, assuming that each one to one association of $\mathrm{K} 2 \mathrm{~A} 1$ and VARC occurs through attachment of four sites. For determination of a global dissociation constant, nonlinear curve fitting was carried out in SEDPHAT v10.58 $8^{51}$ using multiple iterations of the Levenberg-Marquardt algorithm for reduction of global $\chi^{2}$ value. Heats were fitted to a simple hetero-association model $(A+B<->A B)$ without a defined stoichiometry ('n' value). Incompetent (non-reactive) fractions of K2A1 and VARC were kept as dependent variables in the regression model to account for the uncertainty in deriving ' $n$ '

Microscopy. For immunofluorescence microscopy and co-localization studies, sample slides were prepared and images acquired as previously described ${ }^{53}$ Plasmodium falciparum 3D7 infected erythrocytes (iRBCs) synchronized to ring and trophozoite stages were fixed using $4 \%$ paraformaldehyde and $0.0075 \%$ glutaraldehyde. The iRBCs were probed with rabbit anti-VARC antibodies $(1: 500)$ and mouse anti-K2A1 antibodies (1:150) (Bangalore Genei, India). Secondary antibodies used were AlexaFluor488-tagged anti-mouse and AlexaFluor594 tagged anti-rabbit (Invitrogen). Fixed smears were mounted in DAPI Anti-Fade (Invitrogen) and sealed. A smear of uninfected erythrocytes was used as a control.

Co-localization of K2A1 and VARC was visualized on a Nikon A1R confocal laserscanning microscope equipped with diode (405 nm, DAPI), $\operatorname{Ar}(488 \mathrm{~nm}$, AlexaFluor488) and $\mathrm{He}-\mathrm{Ne}(594 \mathrm{~nm}$, AlexaFluor594) lasers. Images were acquired separately for each wavelength and merged, using NIS elements v 3.2 software. Quantitation of co-localization was done using Pearson's correlation and co-localization coefficients $\mathrm{cl}$ and $\mathrm{c}^{31}$, calculated by the 'Colocalization' module in NIS elements software.

1. Cibulskis, R. E., Aregawi, M., Williams, R., Otten, M. \& Dye, C. Worldwide incidence of malaria in 2009: estimates, time trends, and a critique of methods. PLoS Med 8, e1001142 (2011).

2. Maubert, B., Guilbert, L. J. \& Deloron, P. Cytoadherence of Plasmodium falciparum to intercellular adhesion molecule 1 and chondroitin-4-sulfate expressed by the syncytiotrophoblast in the human placenta. Infect Immun $\mathbf{6 5}$, 1251-1257 (1997).

3. MacPherson, G. G., Warrell, M. J., White, N. J., Looareesuwan, S. \& Warrell, D. A. Human cerebral malaria. A quantitative ultrastructural analysis of parasitized erythrocyte sequestration. Am J Pathol 119, 385-401 (1985).

4. Cooke, B. M., Mohandas, N. \& Coppel, R. L. Malaria and the red blood cell membrane. Semin Hematol 41, 173-188 (2004).

5. Baruch, D. I., Rogerson, S. J. \& Cooke, B. M. Asexual blood stages of malaria antigens: cytoadherence. Chem Immunol 80, 144-162 (2002).

6. Su, X. Z. et al. The large diverse gene family var encodes proteins involved in cytoadherence and antigenic variation of Plasmodium falciparum-infected erythrocytes. Cell 82, 89-100 (1995).

7. Baruch, D. I. et al. Cloning the P. falciparum gene encoding PfEMP1, a malarial variant antigen and adherence receptor on the surface of parasitized human erythrocytes. Cell 82, 77-87 (1995).

8. Smith, J. D. et al. Switches in expression of Plasmodium falciparum var genes correlate with changes in antigenic and cytoadherent phenotypes of infected erythrocytes. Cell 82, 101-110 (1995)

9. Crabb, B. S. et al. Targeted gene disruption shows that knobs enable malariainfected red cells to cytoadhere under physiological shear stress. Cell 89, 287-296 (1997).

10. Culvenor, J. G. et al. Plasmodium falciparum: identification and localization of a knob protein antigen expressed by a cDNA clone. Exp Parasitol 63, 58-67 (1987).

11. Pologe, L. G., Pavlovec, A., Shio, H. \& Ravetch, J. V. Primary structure and subcellular localization of the knob-associated histidine-rich protein of Plasmodium falciparum. Proc Natl Acad Sci U S A 84, 7139-7143 (1987).

12. Triglia, T. et al. The complete sequence of the gene for the knob-associated histidine-rich protein from Plasmodium falciparum. EMBO J 6, 1413-1419 (1987).

13. Waller, K. L., Cooke, B. M., Nunomura, W., Mohandas, N. \& Coppel, R. L. Mapping the binding domains involved in the interaction between the Plasmodium falciparum knob-associated histidine-rich protein (KAHRP) and the cytoadherence ligand P. falciparum erythrocyte membrane protein 1 (PfEMP1). J Biol Chem 274, 23808-23813 (1999).

14. Waller, K. L., Nunomura, W., Cooke, B. M., Mohandas, N. \& Coppel, R. L. Mapping the domains of the cytoadherence ligand Plasmodium falciparum erythrocyte membrane protein 1 (PfEMP1) that bind to the knob-associated histidine-rich protein (KAHRP). Mol Biochem Parasitol 119, 125-129 (2002).

15. Voigt, S. et al. The cytoadherence ligand Plasmodium falciparum erythrocyte membrane protein 1 (PfEMP1) binds to the P. falciparum knob-associated histidine-rich protein (KAHRP) by electrostatic interactions. Mol Biochem Parasitol 110, 423-428 (2000).

16. Kjaergaard, M. et al. Temperature-dependent structural changes in intrinsically disordered proteins: formation of alpha-helices or loss of polyproline II? Protein Sci 19, 1555-1564 (2010).

17. Benison, G., Nyarko, A. \& Barbar, E. Heteronuclear NMR identifies a nascent helix in intrinsically disordered dynein intermediate chain: implications for folding and dimerization. J Mol Biol 362, 1082-1093 (2006).

18. Ramachandran, G. N., Ramakrishnan, C. \& Sasisekharan, V. Stereochemistry of polypeptide chain configurations. J Mol Biol 7, 95-99 (1963).

19. Berjanskii, M. V. \& Wishart, D. S. A simple method to predict protein flexibility using secondary chemical shifts. J Am Chem Soc 127, 14970-14971 (2005).

20. Blaber, M., Zhang, X. J. \& Matthews, B. W. Structural basis of amino acid alpha helix propensity. Science 260, 1637-1640 (1993). 
21. Monera, O. D., Sereda, T. J., Zhou, N. E., Kay, C. M. \& Hodges, R. S. Relationship of sidechain hydrophobicity and alpha-helical propensity on the stability of the single-stranded amphipathic alpha-helix. J Pept Sci 1, 319-329 (1995).

22. Chou, P. Y., Wells, M. \& Fasman, G. D. Conformational studies on copolymers of hydroxypropyl-L-glutamine and L-leucine. Circular dichroism studies. Biochemistry 11, 3028-3043 (1972).

23. Vaynberg, J. \& Qin, J. Weak protein-protein interactions as probed by NMR spectroscopy. Trends Biotechnol 24, 22-27 (2006).

24. Wagner, G. Prospects for NMR of large proteins. J Biomol NMR 3, 375-385 (1993)

25. Yao, J., Dyson, H. J. \& Wright, P. E. Chemical shift dispersion and secondary structure prediction in unfolded and partly folded proteins. FEBS Lett 419 , 285-289 (1997).

26. Uversky, V. N. Multitude of binding modes attainable by intrinsically disordered proteins: a portrait gallery of disorder-based complexes. Chem Soc Rev 40, 1623-1634 (2011).

27. Sigalov, A. B., Kim, W. M., Saline, M. \& Stern, L. J. The intrinsically disordered cytoplasmic domain of the $\mathrm{T}$ cell receptor zeta chain binds to the nef protein of simian immunodeficiency virus without a disorder-to-order transition. Biochemistry 47, 12942-12944 (2008).

28. Sigalov, A. B., Zhuravleva, A. V. \& Orekhov, V. Y. Binding of intrinsically disordered proteins is not necessarily accompanied by a structural transition to a folded form. Biochimie 89, 419-421 (2007).

29. Pometun, M. S., Chekmenev, E. Y. \& Wittebort, R. J. Quantitative observation of backbone disorder in native elastin. J Biol Chem 279, 7982-7987 (2004).

30. Rug, M., Prescott, S. W., Fernandez, K. M., Cooke, B. M. \& Cowman, A. F. The role of KAHRP domains in knob formation and cytoadherence of $P$. falciparuminfected human erythrocytes. Blood 108, 370-378 (2006).

31. Adler, J. \& Parmryd, I. Quantifying colocalization by correlation: the Pearson correlation coefficient is superior to the Mander's overlap coefficient. Cytometry A 77, 733-742 (2010).

32. Horrocks, P. et al. PfEMP1 expression is reduced on the surface of knobless Plasmodium falciparum infected erythrocytes. J Cell Sci 118, 2507-2518 (2005).

33. Raventos-Suarez, C., Kaul, D. K., Macaluso, F. \& Nagel, R. L. Membrane knobs are required for the microcirculatory obstruction induced by Plasmodium falciparum-infected erythrocytes. Proc Natl Acad Sci U S A 82, 3829-3833 (1985).

34. Oh, S. S. et al. Plasmodium falciparum erythrocyte membrane protein 1 is anchored to the actin-spectrin junction and knob-associated histidine-rich protein in the erythrocyte skeleton. Mol Biochem Parasitol 108, 237-247 (2000).

35. Leech, J. H., Barnwell, J. W., Miller, L. H. \& Howard, R. J. Identification of a strainspecific malarial antigen exposed on the surface of Plasmodium falciparuminfected erythrocytes. J Exp Med 159, 1567-1575 (1984).

36. Hora, R., Bridges, D. J., Craig, A. \& Sharma, A. Erythrocytic casein kinase II regulates cytoadherence of Plasmodium falciparum-infected red blood cells. J Biol Chem 284, 6260-6269 (2009).

37. Mayer, C., Slater, L., Erat, M. C., Konrat, R. \& Vakonakis, I. Structural analysis of the Plasmodium falciparum erythrocyte membrane protein 1 (PfEMP1) intracellular domain reveals a conserved interaction epitope. J Biol Chem 287, 7182-7189 (2012)

38. Jorda, J., Xue, B., Uversky, V. N. \& Kajava, A. V. Protein tandem repeats - the more perfect, the less structured. FEBS J 277, 2673-2682 (2010).

39. Mittag, T. et al. Dynamic equilibrium engagement of a polyvalent ligand with a single-site receptor. Proc Natl Acad Sci US A 105, 17772-17777 (2008).

40. Acharya, P., Chaubey, S., Grover, M. \& Tatu, U. An Exported Heat Shock Protein 40 Associates with Pathogenesis-Related Knobs in Plasmodium falciparum Infected Erythrocytes. PLoS One 7, e44605 (2012).

41. Appel, R. D., Bairoch, A. \& Hochstrasser, D. F. A new generation of information retrieval tools for biologists: the example of the ExPASy WWW server. Trends Biochem Sci 19, 258-260 (1994).

42. Kyte, J. \& Doolittle, R. F. A simple method for displaying the hydropathic character of a protein. J Mol Biol 157, 105-132 (1982).

43. Wiechelman, K. J., Braun, R. D. \& Fitzpatrick, J. D. Investigation of the bicinchoninic acid protein assay: identification of the groups responsible for color formation. Anal Biochem 175, 231-237 (1988).
44. Wider, G. \& Dreier, L. Measuring protein concentrations by NMR spectroscopy. J Am Chem Soc 128, 2571-2576 (2006).

45. Dreier, L. \& Wider, G. Concentration measurements by PULCON using X-filtered or 2D NMR spectra. Magn Reson Chem 44 Spec No, S206-212 (2006).

46. Keller, R. The computer aided resonance assignment tutorial (CANTINA Verlag, Goldau, 2004).

47. Herrmann, T., Guntert, P. \& Wuthrich, K. Protein NMR structure determination with automated NOE assignment using the new software CANDID and the torsion angle dynamics algorithm DYANA. J Mol Biol 319, 209-227 (2002).

48. Herrmann, T., Guntert, P. \& Wuthrich, K. Protein NMR structure determination with automated NOE-identification in the NOESY spectra using the new software ATNOS. J Biomol NMR 24, 171-189 (2002).

49. Shen, Y., Delaglio, F., Cornilescu, G. \& Bax, A. TALOS+: a hybrid method for predicting protein backbone torsion angles from NMR chemical shifts. J Biomol NMR 44, 213-223 (2009).

50. Su, D. et al. Structural basis for recognition of $\mathrm{H} 3 \mathrm{~K} 56$-acetylated histone $\mathrm{H} 3-\mathrm{H} 4$ by the chaperone Rtt106. Nature 483, 104-107 (2012).

51. Houtman, J. C. et al. Studying multisite binary and ternary protein interactions by global analysis of isothermal titration calorimetry data in SEDPHAT: application to adaptor protein complexes in cell signaling. Protein Sci 16, 30-42 (2007).

52. Coussens, N. P., Schuck, P. \& Zhao, H. Strategies for assessing proton linkage to bimolecular interactions by global analysis of isothermal titration calorimetry data. J Chem Thermodyn 52, 95-107 (2012).

53. Khan, S. et al. Uneven spread of cis- and trans-editing aminoacyl-tRNA synthetase domains within translational compartments of P. falciparum. Sci Rep 1, 188 (2011)

\section{Acknowledgments}

The work was funded by the Department of Biotechnology (DBT), Govt. of India (Grant No. BT/PR13018/BRB/10/731/2009 to N.S.B.). A.K. is a recipient of DBT-Ramalingaswami fellowship. A.K.G. is a recipient of DBT senior research fellowship. The authors wish to thank DBT for providing financial support for the high field NMR spectrometers at the ICGEB, New Delhi and NII, New Delhi. We thank Dr. Pawan Malhotra for critically reading the manuscript and providing useful suggestions. We thank Dr. Amit Sharma for the clones of K2A and VARC. We also thank Dinesh Mohanakrishnan for providing iRBCs.

\section{Author contributions}

N.S.B. designed research; A.K.G., P.R., A.K. and N.S.B. performed research and A.K.G. and N.S.B. analyzed data and wrote the paper.

\section{Additional information}

Accession codes: Accession nos. for nucleotide sequences of PfEMP1 and KAHRP are GenBank: XM_001349477.1 and GenBank: XM_001349498.2, respectively.

Sequence-specific NMR resonance assignments of K2A1 has been deposited in the BioMagResBank database, www.bmrb.wisc.edu [BMRB accession number 19029].

Supplementary information accompanies this paper at http://www.nature.com/ scientificreports

Competing financial interests: The authors declare no competing financial interests.

How to cite this article: Ganguly, A.K., Ranjan, P., Kumar, A. \& Bhavesh, N.S. Dynamic association of PfEMP1 and KAHRP in knobs mediates cytoadherence during Plasmodium invasion. Sci. Rep. 5, 8617; DOI:10.1038/srep08617 (2015).

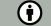

This work is licensed under a Creative Commons Attribution 4.0 International License. The images or other third party material in this article are included in the article's Creative Commons license, unless indicated otherwise in the credit line; if the material is not included under the Creative Commons license, users will need to obtain permission from the license holder in order to reproduce the material. To view a copy of this license, visit http://creativecommons.org/licenses/by/4.0/ 